\title{
STRUCTURE AND PROPERTIES OF FULLY-PENETRATED METAL OF TWO-PHASE TITANIUM ALLOY WITH DISPERSION HARDENING AT AAW
}

\author{
G.M. GRIGORENKO, S.V. AKHONIN, O.M. ZADOROZHNYUK and I.N. KLOCHKOV \\ E.O. Paton Electric Welding Institute, NASU \\ 11 Kazimir Malevich Str., 03680, Kiev, Ukraine. E-mail: office@paton.kiev.ua
}

\begin{abstract}
Tungsten inert gas welding remains the most widespread, relatively easy and versatile method for manufacture of the structures of titanium alloys. Welding can be performed in different spatial positions and equipment can be sufficiently fast readjusted at change of joint type and thickness of metal being welded. Aim of present work lies in study and comparison of a structure and mechanical properties of fully-penetrated metal of high-strength titanium alloys with dispersion hardening and without it, produced using argon-arc method. It is shown that in comparison with titanium alloy VT23 an experimental dispersion-hardened alloy has higher strength indices of fully-penetrated metal, however ductility and impact toughness are extremely low, therefore this type of welding and heat treatment is not recommended for it. 11 Ref., 6 Tables, 16 Figures.
\end{abstract}

Keywords: argon-arc welding, TIG, structure, dispersion hardening, titanium silicides, mechanical properties, heat treatment

Structural high-strength titanium-based alloys due to their unique characteristics, such as high specific strength at keeping satisfactory ductility and high corrosion resistance, have found wide application in aircraft and rocket construction as well as gas-turbine engine production. Thus, for example, a frame design of modern passenger aircrafts has by mass around $15 \%$ of complexly-alloyed titanium alloys and that for military aircrafts makes up to $40 \%$. Further development of aircraft and rocket engineering requires significant increase of service properties of titanium alloys. One of the ways to rise the ultimate strength of such alloys is dispersion hardening of metal due to precipitation of disperse particles from solid solution [1-5].

Tungsten inert gas welding is still one of the most widespread, relatively easy and versatile methods for manufacture of the structures of titanium alloys [6].

In addition to experimental $(\alpha+\beta)$-alloy (close on composition to known Ti-1008 [7] (Table 1), the investigations were also carried out on structure, phase composition and mechanical properties of argon-arc welded joints of commercial high-strength alloy VT23. It is medium $(\alpha+\beta)$-alloy of martensite class, which transfers from $\beta$-phase to martensite form after quenching. This alloy differs from other by increased process ductility that allows using rolling, milling, drawing, stamping, flanging and other operations, related with shaping in process of part manufacture [8].

Rise of alloy doping level promotes for increase of their sensitivity to welding thermal cycle and danger of welded joint brittle fracture due to reduced ductility. Two-phase titanium $(\alpha+\beta)$-alloys considerably increase strength characteristics after aging and quenching. However, high strength of these alloys, with few exceptions, is impossible to realize in the welded structures, that is caused by difficulties, appearing in process of quenching and aging of the structures, and specifically by reduced ductility of welded joints in thermally-hardened state [9].

Aim of this investigation lies in study of effect of TIG welding method on weldability of titanium alloys with dispersion hardening. The results of examination of structure, phase composition and mechanical properties of pilot alloy base metal are described in details in work [7].

Welding heating was carried out by tungsten non-consumable electrode (no filler wire) without full penetration of metal. Welding current made $350 \mathrm{~A}$, welding rate was $10 \mathrm{~m} / \mathrm{h}$ and $12 \mathrm{~V}$ arc voltage.

Table 1 shows composition of examined alloys.

Microstructure of a fully-penetrated metal of experimental alloy No.6 represents coarse elongated grains normal to fusion line (Figure 1). The structure and phase composition are determined by argon-arc welding thermal cycle (Figure 2).

Microhardness of the fully-penetrated metal made $3680 \mathrm{MPa}$, whereas, it reduced to $3430 \mathrm{MPa}$ in HAZ metal, and then in the direction to base metal its value increased to $4010 \mathrm{MPa}$. SEM examination on 
Table 1. Composition of examined alloys, wt.\%

\begin{tabular}{|c|c|c|c|c|c|c|c|c|c|c|}
\hline Alloy & Alloy type & Al & Sn & Zr & Nb & Mo & V & Cr & Fe & Si \\
\hline No.6 & $(\alpha+\beta)$ & 4.29 & 4.39 & 5.95 & 4.26 & 1.57 & 0.68 & 0 & 0 & 0.35 \\
\hline VT23 & $(\alpha+\beta)$ & 4.55 & 0 & $<0.35$ & $<0.15$ & 2.05 & 4.50 & 1.2 & 0.60 & $<0.15$ \\
\hline
\end{tabular}

JAMP9500F unit discovered that the weld disperse particles of complex silicides, which were detected in experimental alloy base metal [7], were virtually almost diluted in process of metal penetration, due to what their identification was impossible. Some amount of nanoparticles of titanium alumosilicides was found along grain boundaries (Figure 3,a). It explains reduction of microhardness in the fully-penetrated metal in comparison with the base metal.

Alternation of $150 \mu \mathrm{m}$ width bands without particles and around $83 \mu \mathrm{m}$ width bands with significant amount of disperse particles (Figure 3, $b$ ) is observed in fusion area of the fully-penetrated metal with the base metal of given specimen. This is the area where the main phase transformations take place (temperature range $890-1668{ }^{\circ} \mathrm{C}$ in Figure 2). Microhardness of this area near fusion line makes $3730 \mathrm{MPa}$, that is, apparently, related with presence of hardening particles of titanium alumosilicides in place of microhardness measurement.

Considerable increase of particle amount is observed in HAZ metal in contrast to fully-penetrated metal structure. Size of complex silicide particles var- ies from $50 \mathrm{~nm}$ to $1 \mu \mathrm{m}$. They are mainly uniformly located in the grain body as well as along the boundaries. Shape of grains approaches to equilibrium, forming triple boundary in the top of their contact (Figure 4).

The most uniform distribution of particles and the maximum microhardness (up to $4010 \mathrm{MPa}$ ) are observed in the base metal. These particles are also located in the grain body as well as along the boundaries. Size of the particles varies in $70-150 \mathrm{~nm}$ range (Figure 5).

Volume fraction of the particles was calculated using STIMAN software. As was shown above, the particles are virtually absent in the weld. Their volume fraction made $0.9 \%$ along the fusion line. Their size and amount in HAZ metal increased to $1.4 \%$ and that in the base metal made $1.9 \%$.

An area, containing all structural constituents, was taken for qualitative determination of phase composition. Table 2 shows composition of disperse hardening particles, $\alpha$-phase and $\beta$-phase of the experimental alloy welded joint. The characteristic spectra were collected from areas for analysis, indicated in Figure 6.
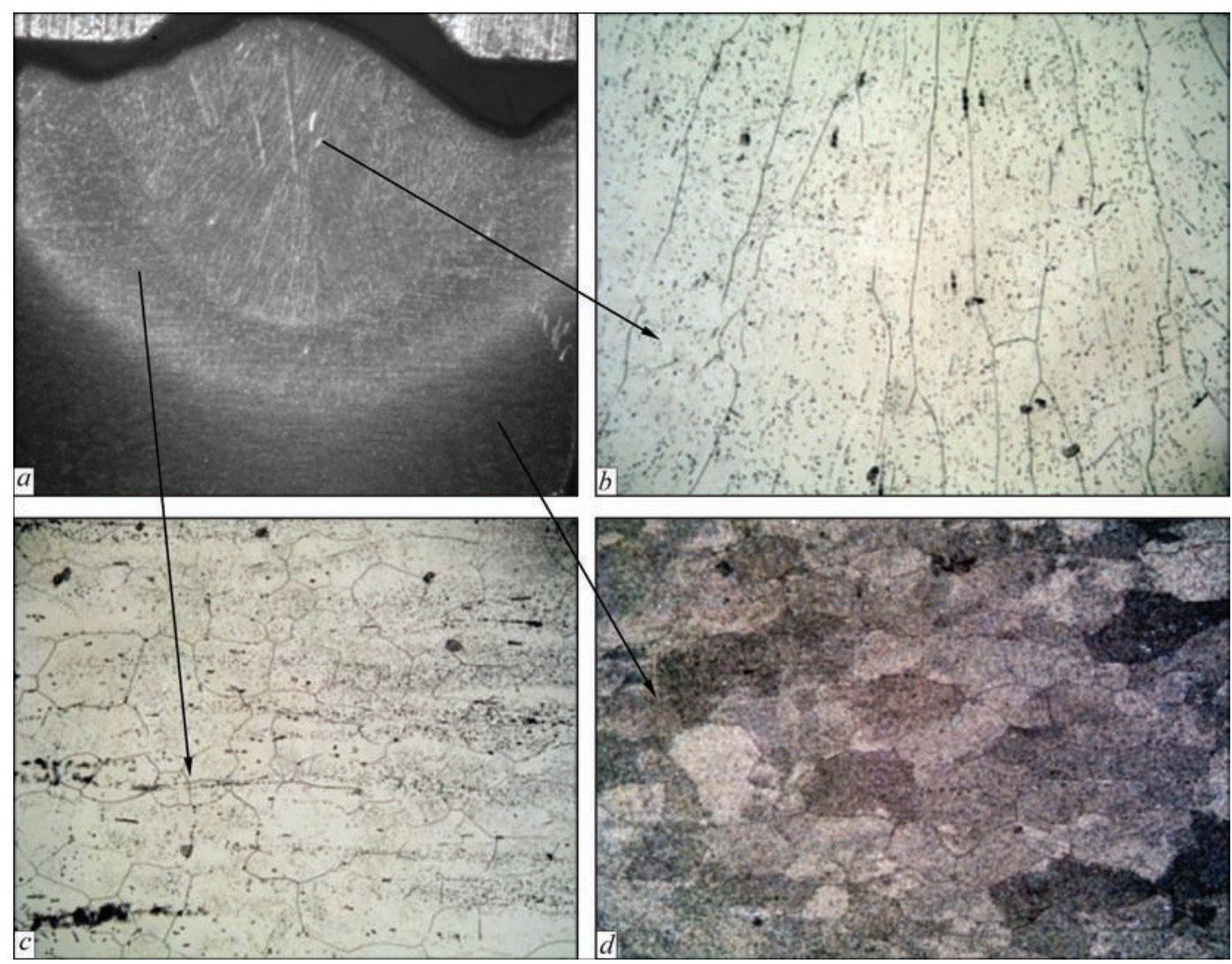

Figure 1. Different areas of alloy No. 6 with fully-penetrated metal, $\times 10(a)$; microstructure of fully-penetrated metal, $\times 100(b)$; microstructure of HAZ metal, $\times 100(c)$; microstructure of base metal, $\times 100(d)$ 


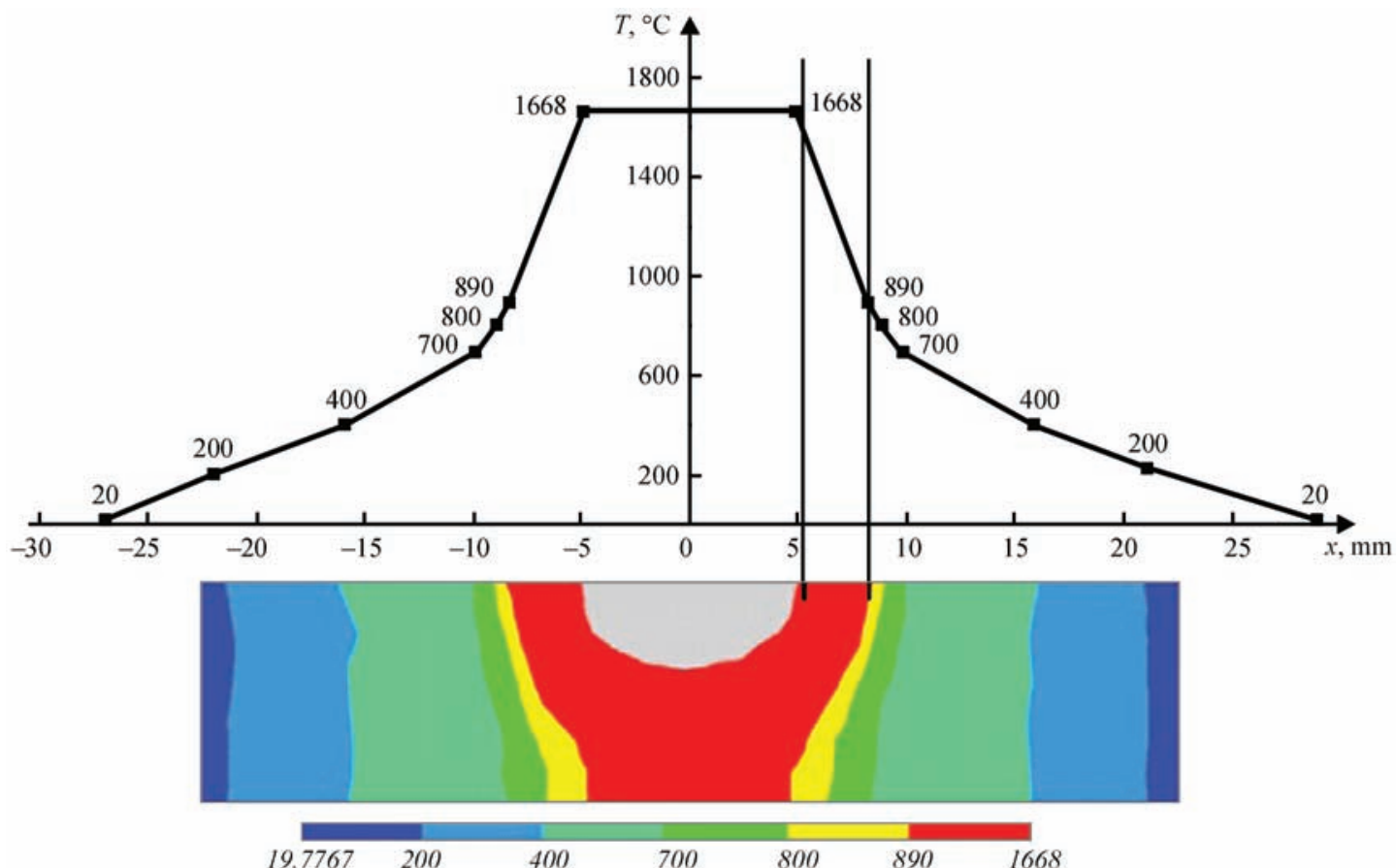

Figure 2. Thermal cycle of argon-arc welding of $(\alpha+\beta)$-titanium alloys

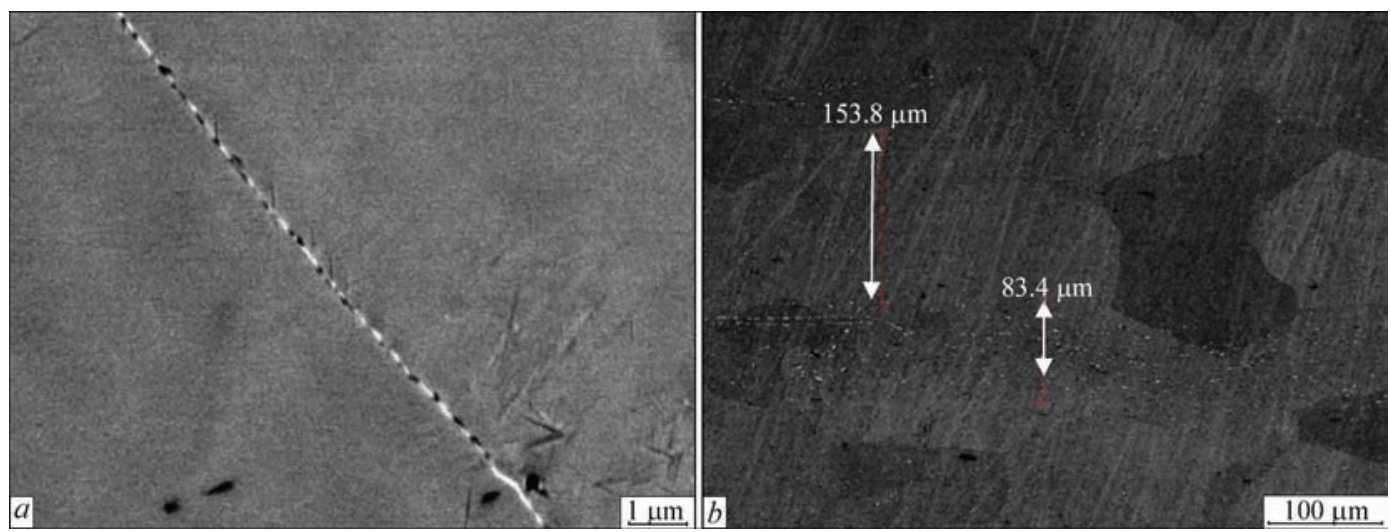

Figure 3. Microstructure of fully-penetrated metal of experimental alloy: $a$ — grain boundary in fully-penetrated metal area, $\times 1000$; $b$ - area of fusion line, $\times 200$

The results of micro X-ray analysis show that analysis of spectra 1 and 2 was carried out in areas of complex silicides (increased content of silicon and zirconium), that in spectrum 3 in area of $\beta$-phase (high

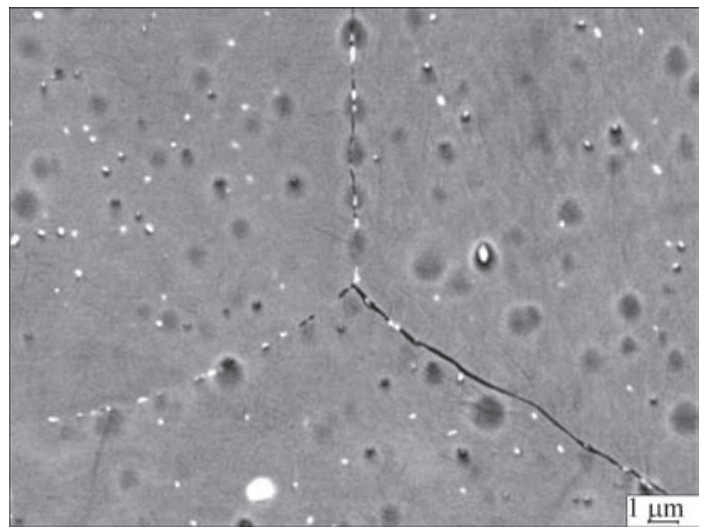

Figure 4. Triple boundary of grains in HAZ metal of experimental alloy, $\times 5000$ content of heavy elements of niobium, molybdenum and vanadium, which differ by light coloring on SEM image), and spectrum 4 in area of $\alpha$-phase with higher aluminum content, respectively.

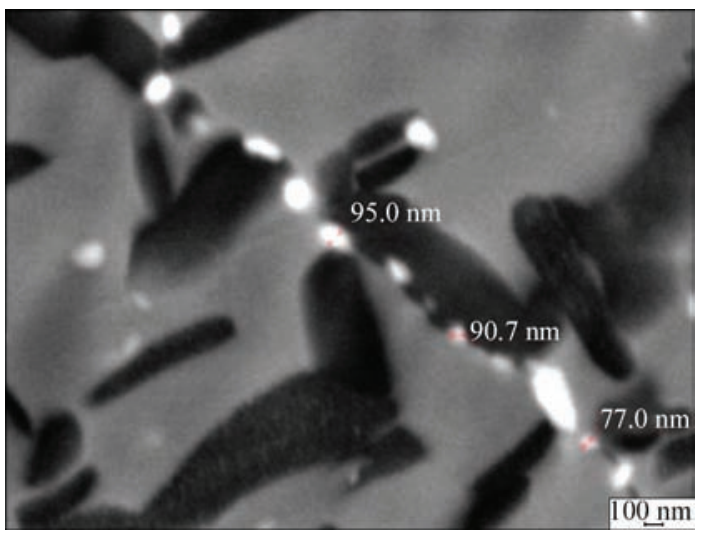

Figure 5. Nature of distribution of particles along base metal grain boundary of experimental alloy, $\times 30000$ 
Table 2. Composition of phase constituents of experimental alloy (wt.\%)

\begin{tabular}{|c|c|c|c|c|c|c|c|c|c|}
\hline $\begin{array}{c}\text { Analysis area } \\
\text { (number of spectrum) }\end{array}$ & $\mathrm{Al}$ & $\mathrm{Si}$ & $\mathrm{Ti}$ & $\mathrm{V}$ & $\mathrm{Zr}$ & $\mathrm{Nb}$ & $\mathrm{Mo}$ & $\mathrm{Sn}$ & Total \\
\hline 1 & 4.24 & 5.36 & 38.70 & 0.00 & 27.24 & 4.61 & 2.50 & 4.28 & 100 \\
\hline 2 & 3.71 & 1.98 & 51.78 & 0.86 & 15.11 & 6.31 & 8.32 & 4.00 & 100 \\
\hline 3 & 2.97 & 0.31 & 58.05 & 5.19 & 7.34 & 9.53 & 13.17 & 2.17 & 100 \\
\hline 4 & 9.40 & 0.18 & 67.15 & 0.67 & 6.73 & 4.07 & 1.33 & 7.42 & 100 \\
\hline
\end{tabular}

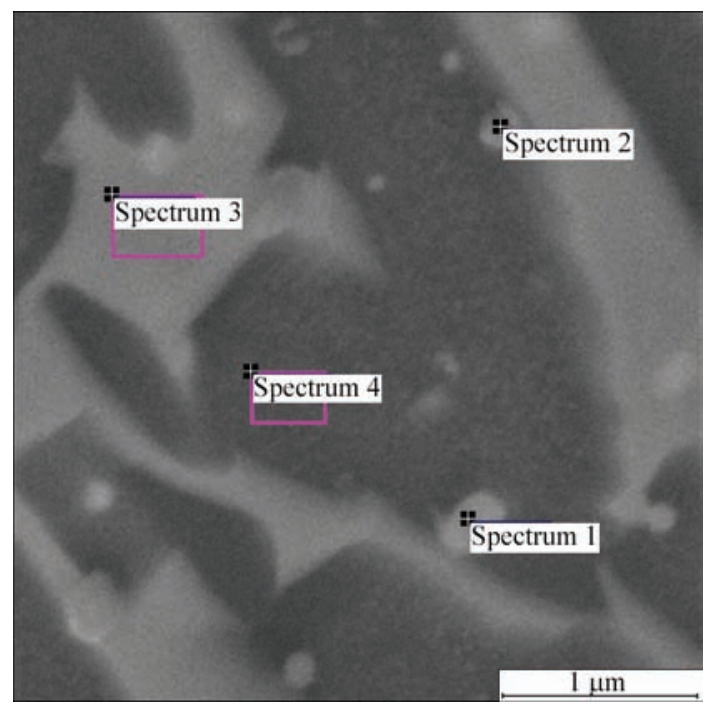

Figure 6. Electron image of analysis areas of energy dispersive spectrometry (EDS), $\times 20000$

Simulation of post-weld furnace heat treatment (HT) was carried out after examinations of structure and phase composition of fully-penetrated metal of ex- perimental alloy. The following heating mode was used, namely to $1000{ }^{\circ} \mathrm{C}$ (1 hour), cooling to $600-650{ }^{\circ} \mathrm{C}$ (1 hour) with further cooling to room temperature.

Microstructure of the fully-penetrated metal of experimental alloy after HT represents itself the same coarse elongated grains as before HT, but there was a crack in the fully-penetrated metal (Figure 7).

Microhardness of the fully-penetrated metal makes $3860 \mathrm{MPa}$, whereas it decreases in HAZ metal to 3600-3200 values, and rises insignificantly to $3580 \mathrm{MPa}$ value in the base metal. Thus, the fully-penetrated metal after HT is characterized by maximum hardness and strength, but at the same time low ductility that results in crack formation.

After heat treatment the area of fully-penetrated metal contains significant amount of uniformly located hardening disperse particles of different size (Figure 8) that provides for increased value of microhardness in comparison with HAZ and base metal.

The particles of smaller size and in lower amount were found in HAZ. The particles of coarser size are

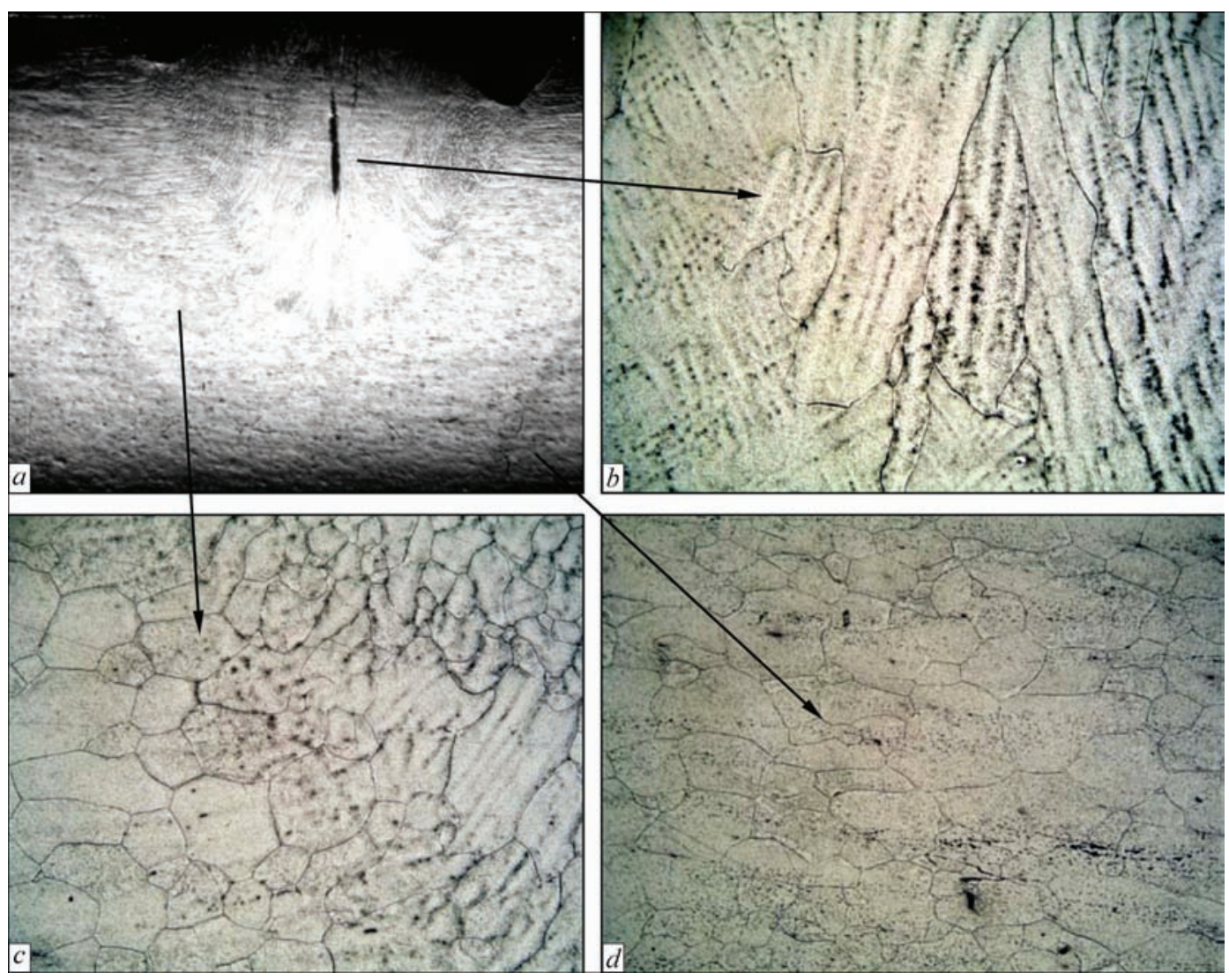

Figure 7. Macrostructure of fully-penetrated metal of experimental alloy after HT, $\times 10(a)$; microstructure of area of fully-penetrated metal, $\times 100(b)$; microstructure of HAZ metal, $\times 100(c)$; microstructure of base metal, $\times 100(d)$ 
observed in the base metal. Volume fraction of particles in the area of fully-penetrated metal makes $1.9 \%$, that in HAZ is $1.7 \%$, and $2.1 \%$ in the base metal. This, probably, indicates that the large amount of particles in the fully-penetrated metal grows in size due to high temperature during HT process. Their volume fraction in the base metal is somewhat higher due to their size coarsening.

Examinations of grain boundaries and composition of the particles of experimental alloy after HT were carried out on scanning electron high resolution microscope TESCAN MIRA 3 LMU with OXFORD INSTRUMENTS INCA ENERGY + microanalysis system.

Significant accumulation of the hardening spherical particles is observed along the boundaries of weld grains. Their sizes are varied in wide limits, i.e. from $50 \mathrm{~nm}$ to $1 \mu \mathrm{m}$ (Figure 9, a). Coagulated silicides were also found (Figure 9, $b$ ) along the boundaries. Such conglomerates along the grain boundaries pro-

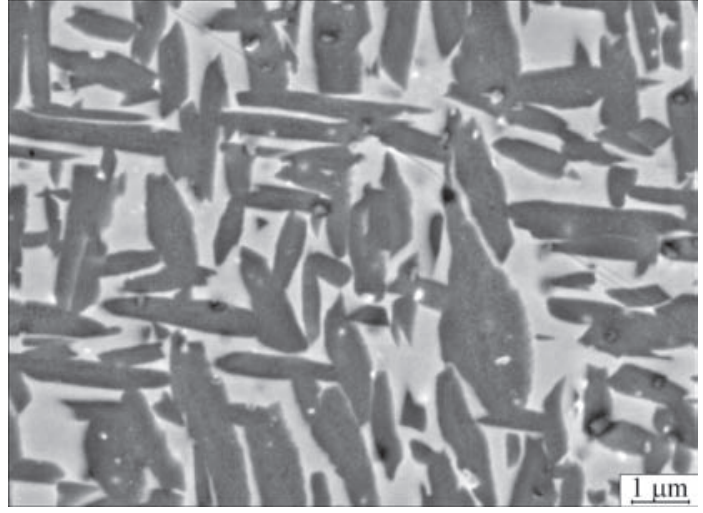

Figure 8. Distribution of disperse particles of complex silicides on surface of microsection of pilot experimental after HT, $\times 10000$ mote large internal stresses that can be a possible reason of crack formation.

The results of examinations of the fully-penetrated experimental two-phase alloy were compared with the results of examination of commercial alloy VT23.

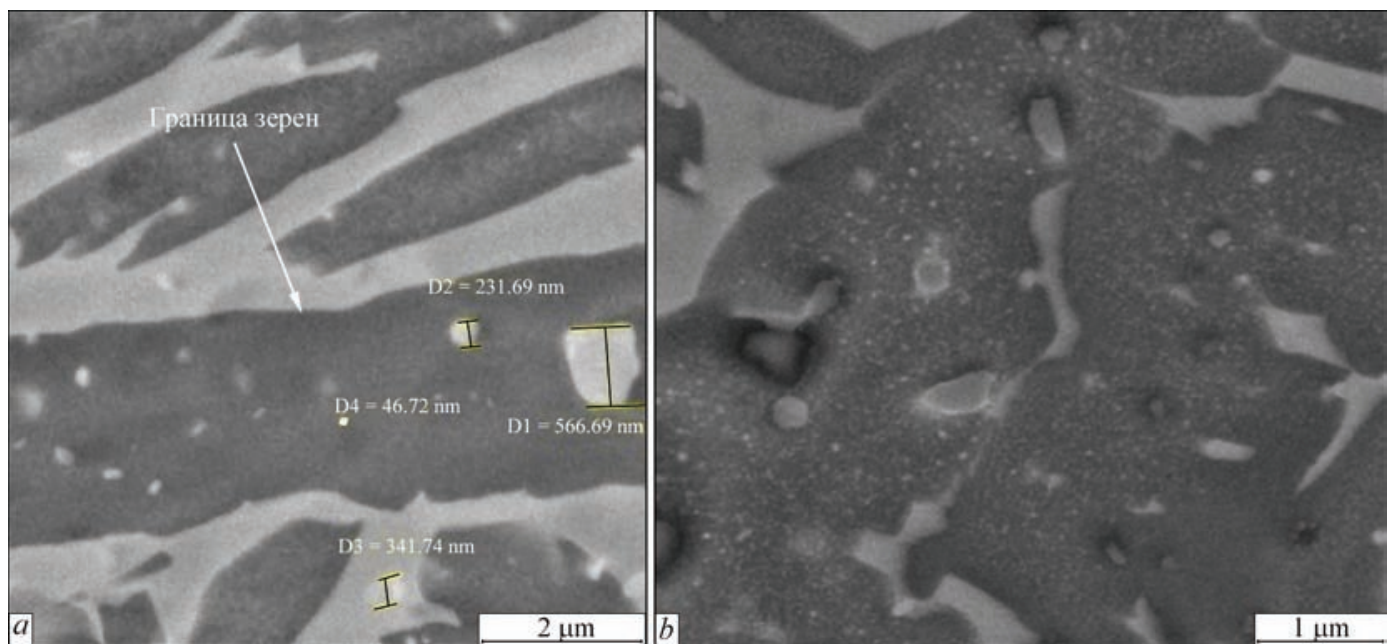

Figure 9. Image in backscattered electrons of grain boundary in area of fully-penetrated metal of alloy No.6 after HT: $a$ - area of grain boundaries with particles, 7000; $b$ - coagulated silicides along grain boundary, $\times 20000$

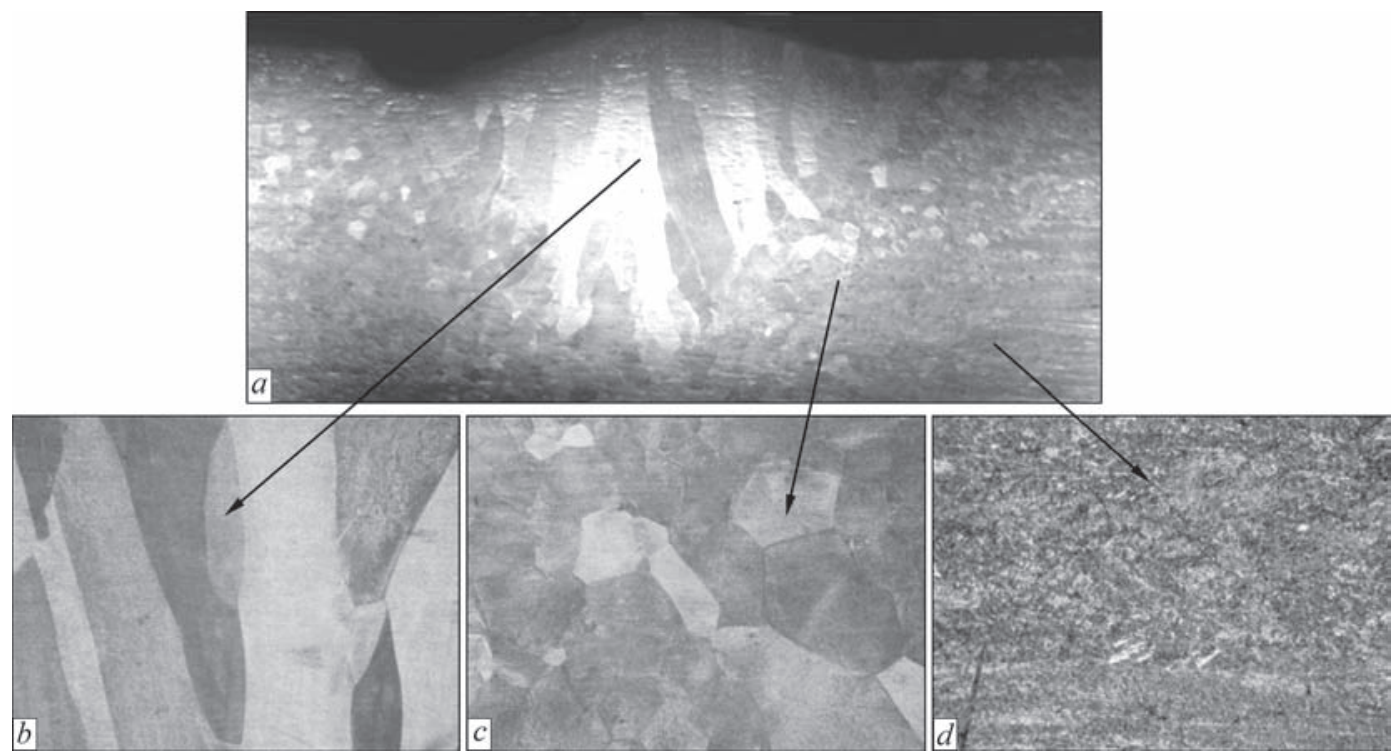

Figure 10. Macrostructure of fully-penetrated metal of alloy VT23, $\times 10(a)$; microstructure in the center of fully-penetrated metal, $\times 50$ (b); microstructure of HAZ metal area, $\times 50(c)$; microstructure of base metal, $\times 100(d)$ 
Table 3. Composition of $\alpha$ and $\beta$-phases of fully-penetrated alloy VT23 (wt.\%)

\begin{tabular}{|c|c|c|c|c|c|c|c|c|}
\hline $\begin{array}{c}\text { Area of analysis } \\
\text { (number of spectrum) }\end{array}$ & $\mathrm{Al}$ & $\mathrm{Si}$ & $\mathrm{Ti}$ & $\mathrm{V}$ & $\mathrm{Cr}$ & $\mathrm{Fe}$ & Mo & Total \\
\hline 1 & 4.21 & 0.20 & 82.03 & 5.63 & 1.23 & 0.65 & 3.92 & 100 \\
\hline 2 & 3.51 & 0.34 & 76.22 & 8.06 & 2.20 & 2.20 & 5.04 & 100 \\
\hline
\end{tabular}

Macrostructure of the fully-penetrated metal of alloy VT23 has virtually no difference from macrostructure of the experimental alloy (Figure 10, $a$ ). The same elongated coarse grains normal to fusion line (Figure $10, b)$ are observed. Microhardness of the area of fully-penetrated metal makes 3550-3560 MPa. The areas of coarse grain, but of more equilibrium type (Figure 10, c) are also observed at transfer in HAZ. Microhardness in HAZ metal rises to 3750-3950 MPa values. The base metal of VT23 welded joint contains a two-phase structure (Figure 10, $d$ ) with microhardness value of around $3200 \mathrm{MPa}$. Such a distribution of microhardness is related with the fact of formation in the fully-penetrated metal and HAZ metal of metastable $\alpha^{\prime \prime}$-phase of martensite type, which differ by high hardness. Besides this, precipitation of $\alpha_{1}$-phase (low-temperature modification of $\alpha$-phase), which is more ductile [10], takes place in the fully-penetrated metal.

Examinations of structure of the fully-penetrated metal of commercially developed alloy VT23, made using SEM TESCAN MIRA 3 LMU, showed that the area of fully-penetrated metal, HAZ and base metal has pure grain boundaries without embrittling precipitations, pores and microcracks (Figure 11).

Analysis of composition of VT23 alloy fully-penetrated metal (Table 3 in Figure 11) was carried out in the same way as in the case of experimental alloy.

The fully-penetrated metal of titanium alloys No.6 and VT23 after argon-arc welding simulation was subjected to tensile and impact tests. The results of mechanical tests are given in Table 4.

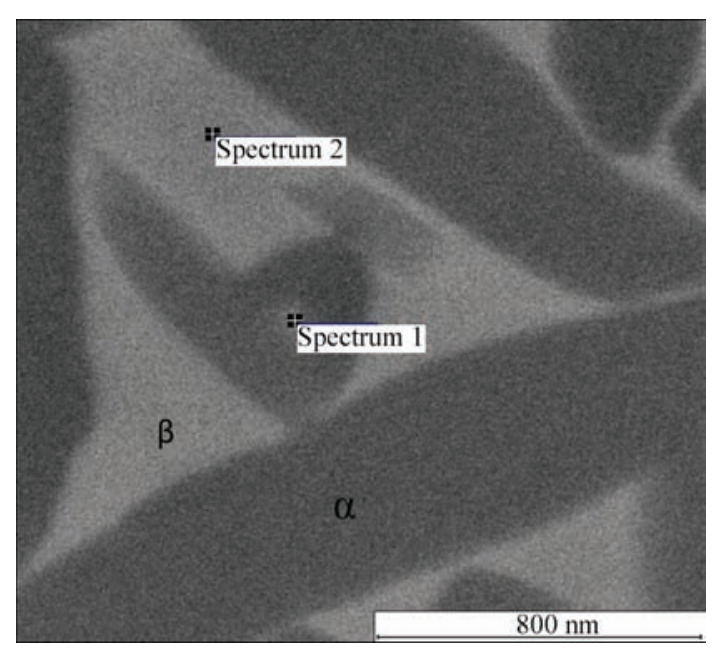

Figure 11. Image in backscattered electrons of microstructure of grain boundary in the VT23 weld, $\times 30000$
Specimen of alloy No.6 was broken in a grip place in tensile testing of the cylinder specimens. This, probably, is related with the fact that all loading falls at the area with microcracks. Due to this non-typical for given alloy low strength was received. Therefore, additional compression tests were carried out (testing machine UTM-100 with maximum loading $100 \mathrm{kN}$ ). The results of mechanical compression tests are given in Table 5.

Thus, the ultimate strength of the fully-penetrated metal was received in compression testing and it makes $80 \%$ of base metal ultimate strength $\left(K_{t}=0.8\right)$, and yield strength of the fully-penetrated metal was even larger than the base metal indices.

Fracture surface after impact tests of Charpy specimens in the area of fully-penetrated metal represents itself a local area, formed on microchip mechanism (Figure 12). Its presence indicates a quasi-brittle nature of this metal area fracture. The microcracks can be seen at larger magnifications (Figure 13).

The same as in the case of microsection examination, no disperse particles of titanium alumosilicides were found on the fracture surface. This verifies an earlier expressed idea that these particles are partially melted and can not be identified due to high temperature and duration of argon-arc process. It is agreed with the possibility of invertible flow of dispersion mechanism [11]. Composition of the fully-penetrated metal area corresponds to matrix content, and the particles are not found.

After HT of alloy No.6 fully-penetrated metal, it was also subjected to mechanical impact and tensile

Table 4. Mechanical properties of base metal and fully-penetrated alloys No.6 and VT23

\begin{tabular}{|c|c|c|c|c|c|}
\hline \multicolumn{2}{|c|}{ Alloy } & $\sigma_{y}, \mathrm{MPa}$ & $\sigma_{\mathrm{t}}, \mathrm{MPa}$ & $K C V, \mathrm{~J} / \mathrm{cm}^{2}$ & $\Delta, \%$ \\
\hline \multirow{2}{*}{ VT23 } & BM & 1050 & 1200 & 42 & 5 \\
\cline { 2 - 6 } & $\begin{array}{c}\text { Fully-pene- } \\
\text { trated metal }\end{array}$ & 1084 & 1128 & 29.6 & 1.3 \\
\hline \multirow{2}{*}{ No.6 } & BM & 1330 & 1420 & 4 & 1 \\
\cline { 2 - 6 } & $\begin{array}{c}\text { Fully-pene- } \\
\text { trated metal }\end{array}$ & - & 560 & $<1$ & $<1$ \\
\hline
\end{tabular}

Table 5. Mechanical properties of base metal and fully-penetrated alloy No.6 in compression testing

\begin{tabular}{|c|c|c|c|c|}
\hline \multicolumn{2}{|c|}{ Alloy } & $\sigma_{y}$, MPa & $\sigma_{t}$, MPa & $\psi, \%$ \\
\hline \multirow{2}{*}{ No.6 } & BM & 1220 & 1850 & 6 \\
\cline { 2 - 5 } & Fully-penetrated metal & 1315 & 1440 & 2.5 \\
\hline
\end{tabular}




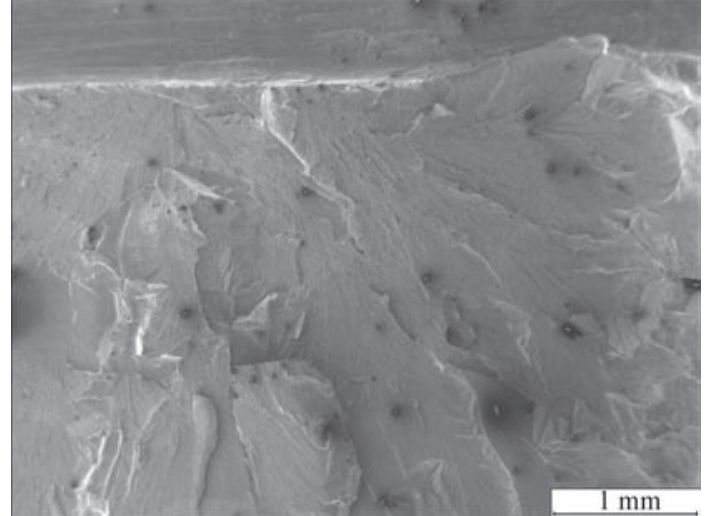

Figure 12. Fracture surface of fully-penetrated metal of experimental alloy, $\times 25$

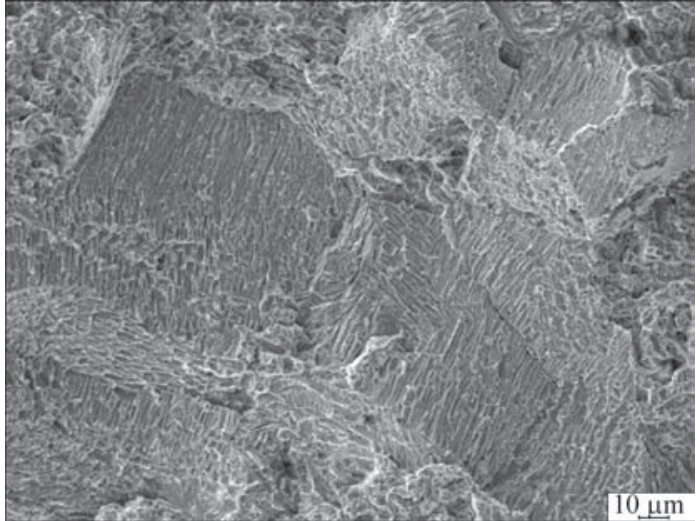

Figure 14. Fracture surface of experimental alloy specimen after $\mathrm{HT}, \times 500$

Table 6. Composition of structure constituents of fracture of alloy No.6 fully-penetrated metal after HT, wt.\% (on Figure 15, a)

\begin{tabular}{|c|c|c|c|c|c|c|c|c|c|}
\hline $\begin{array}{c}\text { Area of analysis } \\
\text { (number of spectrum) }\end{array}$ & $\mathrm{Al}$ & $\mathrm{Si}$ & $\mathrm{Ti}$ & $\mathrm{V}$ & $\mathrm{Zr}$ & $\mathrm{Nb}$ & Mo & Sn & Total \\
\hline 1 & 3.83 & 8.45 & 38.89 & 1.21 & 35.63 & 3.48 & 1.38 & 4.77 & 100 \\
\hline 2 & 3.72 & 9.44 & 38.94 & 0.38 & 38.75 & 1.84 & 0.43 & 4.57 & 100 \\
\hline 3 & 8.50 & 0.24 & 70.43 & 1.52 & 6.10 & 3.55 & 0.73 & 7.79 & 100 \\
\hline
\end{tabular}

tests. Small magnifications show the chip areas with equiaxial coarse grain structure (Figure 14).

If large magnifications revealed only microcracks directly after argon-arc welding simulation, than in this case secondary intergranular cracks can be obviously observed even at 500 fold magnification. This indicates high sensitivity of this alloy to HT heating.

At large magnifications considerable amount of disperse hardening particles as well as microcracks were found. They are located along the boundaries and grain body. In HT the particles increased in size to values which can be identified using SEM. They are located in the fracture pits that indicate more ductile fracture type of metal. Low level of ductility of this material can be related with increase of amount and extension of microcracks due to temperature gradient in HT heating. Detected particles have different size from $1 \mu \mathrm{m}$ to $50 \mathrm{~nm}$. Nature of particle distribution and chemical analysis of phase constituents are presented in Figure 15 and in Table 6 (on Figure 15, a).
The results of chemical analysis show that all the particles, which are detected on the fracture surface after HT are titanium alumosilicides. HT promotes for rise of their size to $50 \mathrm{~nm}$ and more.

Fractographic analysis of the fracture surface was also carried out after mechanical tests of commercial high-strength alloy VT23.

The fracture surface is less brittle in comparison with experimental alloy (Figure 16) that verifies higher indices of impact toughness and ductility.

Thus, the following can be concluded after examination of the fully-penetrated metal of experimental dispersion-hardened $(\alpha+\beta)$-titanium alloy and commercial high-strength $(\alpha+\beta)$-titanium alloy VT23, received by TIG:

- directly after welding simulation, hardening titanium alumosilicides in area of the fully-penetrated metal are partially dissolved due to long-term effect of high temperature, i.e after TIG the fully-penetrated metal of experimental alloy is not dispersion-hard-

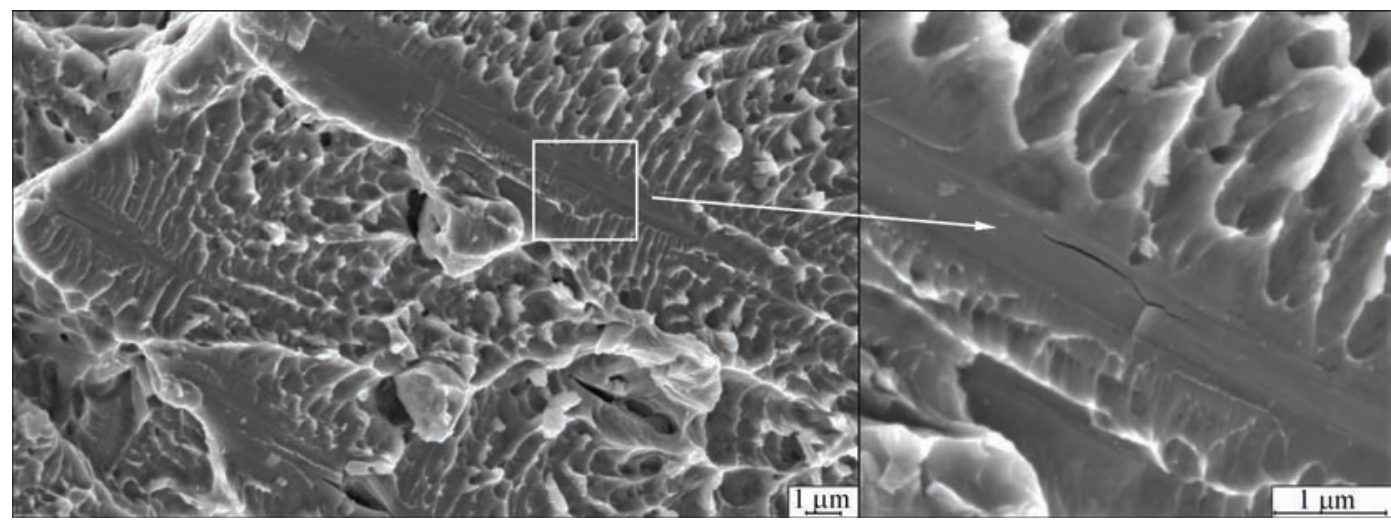

Figure 13. Fracture area of experimental alloy with microcracks, $\times 5000(\times 20000)$ 


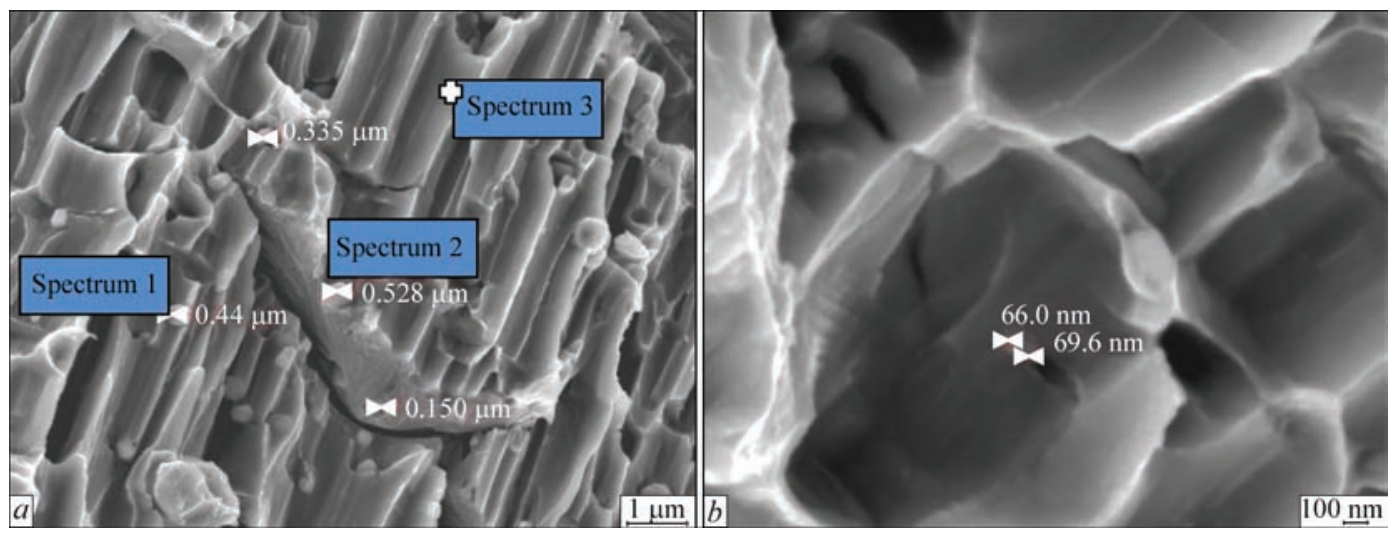

Figure 15. Fracture of fully-penetrated metal of experimental alloy after HT: $a$ - hardening particles and microcracks, $\times 10000 ; b-$ nanoparticles in fracture pit and nanosize cracks, $\times 40000$
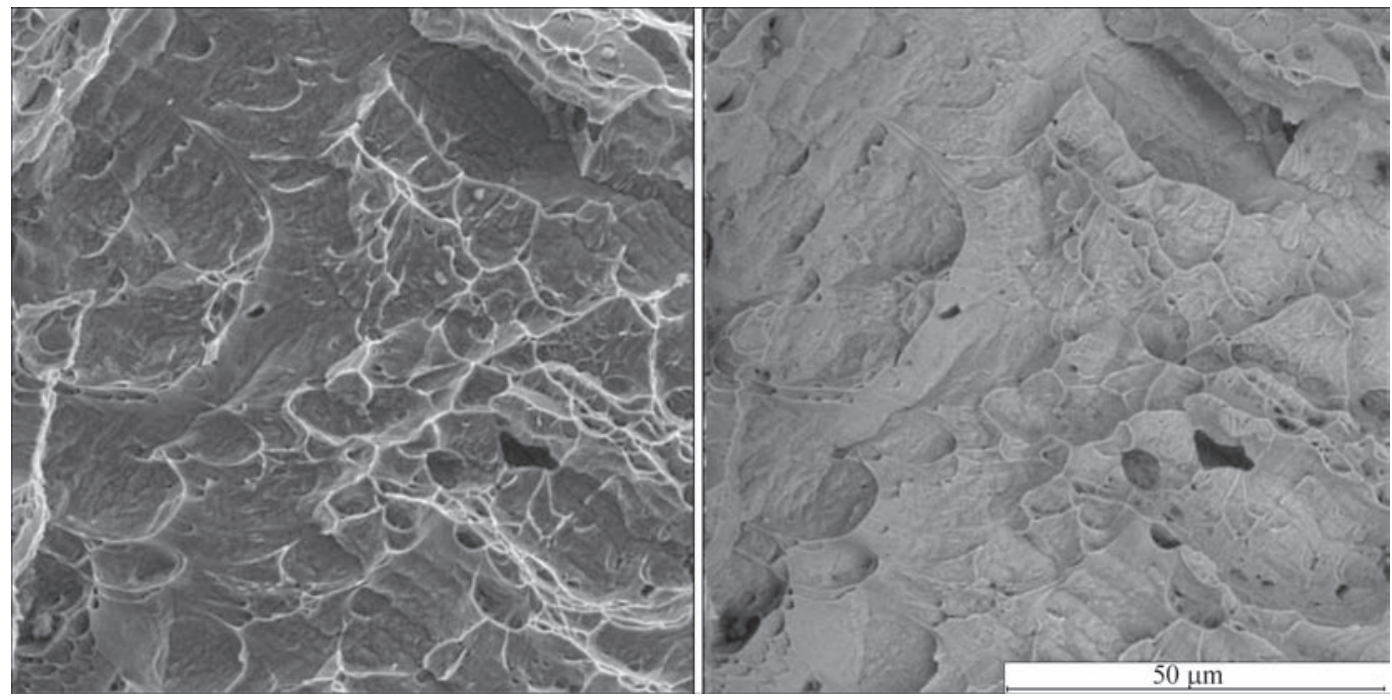

Figure 16. Fracture of fully-penetrated metal of VT23 alloy: $a$ - in the secondary electrons; $b$ - in backscattered, $\times 4000$

ened, but contains solid-solution hardening. Besides, the microcracks, caused by post-weld stresses, are observed at larger magnifications;

- coarsening of the hardening particles due to coagulation processes takes place after HT. These particles promote for more ductile fracture on pit tear mechanism. The microcracks increase in size and amount and result in crack in the middle of the fully-penetrated metal. This takes place due to temperature gradient in HT heating;

- in comparison with commercial high-strength $(\alpha+\beta)$-titanium alloy VT23, experimental dispersion-hardened alloy has higher indices of strength, but extremely low ductility and impact toughness, therefore this type of welding and HT can not be recommended for it.

1. Goldshtejn, M.I., Grachev, S.V., Veksler, Yu.G. (1985) Special steels: Manual for inst. of higher education. Moscow: Metallurgiya.

2. Rzhevskaya S.V. (2004) Materials science: Manual. Moscow: Logos.

3. (2003) Metals and alloys: Refer. Book. Ed. by Yu.P. Solntsev. St.-Petersburg: NPO Professional.

4. Trefilov, V.I. (1987) Strain hardening and fracture of polycrystalline metals.

5. Bochvar, A.A. (2012) Increase in strength or hardening of materials. http://do.gendocs.ru/docs/index-233261.html

6. Zamkov, V.N. (1986) Metallurgy and technology of welding of titanium and its alloys. Kiev: Naukova Dumka.

7. Grigorenko, G.M., Akhonin, S.V., Taranova, T.G. et al. (2012) Dispersion-hardened titanium alloys of Ti-Si-X system. Sovremennaya Elektrometallurgiya, 1, 45-53.

8. NPO Titan. Information. http://www.npctitan.ru/spravka/alloys/23/

9. Glazunov, S.G., Moiseev, V.N. (1974) Structural titanium alloys. Moscow: Metallurgiya.

10. Akhonin, S.V., Belous, V.Yu., Muzhichenko, A.F. et al. (2013) Mathematical modeling of structural transformations in HAZ of titanium alloy VT23 during TIG welding. The Paton Welding J., 3, 24-27.

11. Grigorenko, G.M., Zadorozhnyuk, O.M. (2012) Dispersion hardening as a way to increase the properties of new generation titanium alloys. Sovremennaya Elektrometallurgiya, 4, $42-50$.

Received 12.04.2016 